\title{
The Analysis and Test for the Steering Process of Tracked Vehicles on the Hard Road
}

\author{
Wang Hong-yan ${ }^{1, a}$, Li Hao-zhan ${ }^{1, \mathrm{~b}}$, Wang Tao ${ }^{1, \mathrm{c}}$, \\ Rui Qiang1,d, \\ Department of Mechanical Engineering \\ Academy of Armored Force Engineering, \\ Beijing, 100072, China \\ bemail, haozhan8932@163.com \\ Phone +86-10-66717575
}

\author{
Ge Jiang-tao ${ }^{2, e}$, Zhou Guang-ming ${ }^{2, f}$,Yuan $\mathrm{Yi}^{2 \text {, e }}$ \\ Science and Technology on Vehicle Transmission \\ Laboratory, \\ China North Vehicle Research Institute, Beijing 100072, \\ China \\ email
}

\begin{abstract}
Steering performances of tracked vehicle considering the skid of tracks-contact-ground has been studied. Models of traction force, brake force, turning resistance moment, turning radius and turning angular speed were established under the conditions of uniform pressure distribution and concentrated ground-contact-load distribution for the steering. Plane motion equations were solved by means of iterations. A real vehicle was carried out to compare with the models. The results show that the models are reasonable in the state of uniform pressure distribution. On hard road surface, turning radius is larger than that given by the traditional steering theory, and turning angular speed is lower than that consumed by the traditional steering theory. The situation that steering with concentrated contact-groundload needs more driving wheel torque suits the fact better.
\end{abstract}

Keywords-component; tracked vehicle; track pressure on groun; plan motion for steering; skid; slip; test of steering

\section{INTRODUCTION}

The complexity of the interaction between track and ground makes the results of practical steering situation difficult to be used in practical project. The results from traditional theory which is not considered about the skid and slip suit engineering estimation more[1-2].but the results depended on traditional theory have big disparity from actual value. This literature studied the steering performance of tracked vehicle considering the skid on solid ground, but the conclusions can't apply to other steering problems on the ground except solid ground. on above basis, discuss steering problems considering the skid under the conditions of uniform and concentrated pressure distribution for the steering. The research work supposed that the condition is as follows:

a. In geometry, its longitudinal and crosswise is symmetric , and the center of geometry superposition of center of mass projection is concurrent with vehicles plane in horizontal plane

b. Tracked vehicle for low-speed even steering without taking into account the influence of centrifugal force.

c. The tracks are the even supple belts without counting its width influence d. Running resistance coefficient of steering is the same with that in straight line drive

e. The coefficient of friction between tracks and ground, namely the steering resistance coefficient is the isotropism.

\section{TRACTION FORCE, BRAKE FORCE, TURNING RESISTANCE MOMENT}

A. The model of traction force of outside track and brake force of inside track

when assume that the force of track-contact-ground is uniform distribution, we can get traction force of outside track by integral method[1]

$$
F_{y 2}=\frac{G \mu a_{2}}{4} \ln \frac{\sqrt{1+a_{2}^{2}}+1}{\sqrt{1+a_{2}^{2}}-1}
$$

Where, $a_{2}=A_{2} /(L / 2)$

In the same way, the brake force of inside track is

$$
F_{y 1}=-\frac{G \mu a_{1}}{4} \ln \frac{\sqrt{1+a_{1}^{2}}+1}{\sqrt{1+a_{1}^{2}}-1}
$$

When the pressure is concentrated, We can get the results below by the same way

$$
\begin{aligned}
& F_{y 2}=\frac{G \mu}{2 n} \sum_{i=1}^{n} \frac{a_{2}}{\sqrt{Y_{i}^{2}+a_{2}^{2}}} \\
& F_{y 1}=\frac{G \mu}{2 n} \sum_{i=1}^{n} \frac{a_{1}}{\sqrt{Y_{i}^{2}+a_{1}^{2}}}
\end{aligned}
$$


Where, $\mathrm{n}$ is the number of roadwheel; $Y_{i}=y_{i} /(L / 2)$ is the i-th roadwheel relative position, where, $y_{i}$ is the i-th roadwheel position of $\mathrm{Y}$ coordinate(m).

\section{B. Steering resistance moment model}

Assume that the pressure on the ground is uniform distribution, dy is the infinitesimal of the longitudinal axis point $\mathrm{P}_{2}$, so the component force of tangential reaction force on axis $\mathrm{x}$ is

$$
d F_{x 2}=d F_{2} \cos (\pi+\beta)
$$

Where $\cos (\pi+\beta)=-v_{\mathrm{a} x 2} / \sqrt{v_{\mathrm{a} y 2}^{2}+v_{\mathrm{a} x 2}^{2}}$

$d F_{x 2}$ takes rectangle of the track geometry center to form the unit steering resistance coefficient. We can get $M_{\mathrm{r} 2}$ by integral along the entire track length

$$
M_{\mathrm{r} 2}=-\int_{-L / 2}^{L / 2} y q \mu \cdot \dot{\theta} y / \sqrt{\left(\dot{\theta} A_{2}\right)^{2}+(\dot{\theta} y)^{2}} \mathrm{~d} y
$$

After the integral

$$
M_{\mathrm{r} 2}=-\frac{G \mu L}{8}\left(\sqrt{1+a_{2}^{2}}-\frac{a_{2}^{2}}{2} \ln \frac{\sqrt{1+a_{2}^{2}}+1}{\sqrt{1+a_{2}^{2}}-1}\right)
$$

By the same way, steering resistance coefficient of inside track is

$$
M_{\mathrm{r} 1}=-\frac{G \mu L}{8}\left(\sqrt{1+a_{1}^{2}}-\frac{a_{1}^{2}}{2} \ln \frac{\sqrt{1+a_{1}^{2}}+1}{\sqrt{1+a_{1}^{2}}-1}\right)
$$

Total steering resistance coefficient is

$$
M_{\mathrm{r}}=M_{\mathrm{r} 1}+M_{\mathrm{r} 2}
$$

When $\alpha_{1} \rightarrow 0, \alpha_{2} \rightarrow 0, M_{r} \rightarrow-G \mu L / 4$, namely the ideal expression without considering skid and slip.

Steering resistance moment under the pressure of trackcontact-ground concentrated distribution is

$$
M_{\mathrm{r}}=-\frac{G \mu L}{4 n} \sum_{i=1}^{n}\left(\frac{Y_{i}^{2}}{\sqrt{Y_{i}^{2}+a_{2}^{2}}}+\frac{Y_{i}^{2}}{\sqrt{Y_{i}^{2}+a_{1}^{2}}}\right)
$$

\section{KINEMATICS MODEL OF TURNING PROCESS}

Turning radius considering the skid and slip can be obtained by tracked vehicle steering geometric relations. we can get the formula from figure 1

$$
\left\{\begin{array}{l}
\dot{\theta}\left(R-\frac{B}{2}\right)-v_{1}=\dot{\theta} A_{1} \\
-\dot{\theta}\left(R+\frac{B}{2}\right)+v_{2}=\dot{\theta} A_{2}
\end{array}\right.
$$

From above formula, we can get relative turning radius and turning angular velocity considering the skid and slip of track-contact-ground

$$
\begin{gathered}
\rho=\frac{1}{2} \frac{\left(1+\lambda a_{1}\right)+K_{\mathrm{V}}\left(1+\lambda a_{2}\right)}{1-K_{\mathrm{V}}} \\
\dot{\theta}=\frac{v_{2}-v_{1}}{B+A_{2}+A_{1}}
\end{gathered}
$$

Where $v_{2} 、 v_{1}$ is the winding speed of outside and inside track(m·s-1); steering speed ratio $K_{\mathrm{v}}=v_{1} / v_{2}$ define it the ratio of winding speed of inside and outside track.

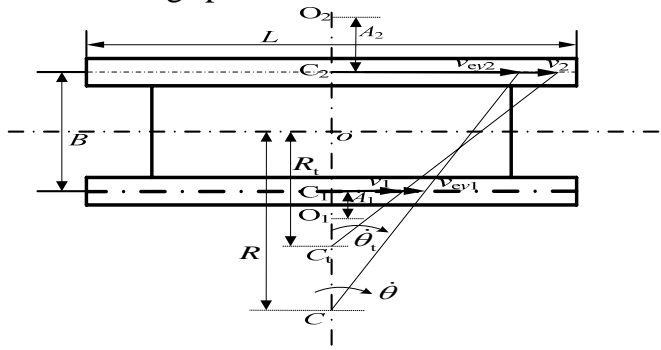

Figure.1 comparison between theoretical and actual steering

\section{MOTION EQUATION OF TRACKED VEHICLE STEERING PLANE}

Analyze the uniform low speed steering of tracked vehicle on a horizontal surface, using the plane motion equation of rigid body system, we can know

$$
\left\{\begin{array}{l}
F_{y 2}+F_{y 1}+F_{\mathrm{R} 2}+F_{\mathrm{R} 1}=0 \\
\left(F_{y 2}-F_{y 1}\right) \frac{B}{2}+M_{\mathrm{r}}=0
\end{array}\right.
$$

Where $F_{\mathrm{R} 1}=F_{\mathrm{R} 2}=-f G / 2$ is the running resistance of vehicles, and $f$ is the coefficient of running resistance

Put the formula (1)、(2)、(7) into equation set(12) and simplify to get the plane motion equation when the pressure is uniform distribution

$$
\left\{\begin{array}{l}
\frac{\alpha_{2}}{4} \ln \frac{\sqrt{1+a_{2}^{2}}+1}{\sqrt{1+a_{2}^{2}}-1}-\frac{a_{1}}{4} \ln \frac{\sqrt{1+a_{1}^{2}}+1}{\sqrt{1+a_{1}^{2}}-1}-f / \mu=0 \\
\left(\begin{array}{l}
\left.a_{2}+\frac{a_{2}^{2} \lambda}{2}\right) \ln \frac{\sqrt{1+a_{2}^{2}}+1}{\sqrt{1+a_{2}^{2}}-1}+ \\
\left(a_{1}+\frac{a_{1}^{2} \lambda}{2}\right) \cdot \ln \frac{\sqrt{1+a_{1}^{2}}+1}{\sqrt{1+a_{1}^{2}}-1}-\lambda\left(\sqrt{1+a_{2}^{2}}\right. \\
+\sqrt{1+a_{1}^{2}}
\end{array}\right)=0
\end{array}\right.
$$


Put (3)、 (4)、 (8) into (13) to get the plane motion equation of steering, when the pressure is concentrated

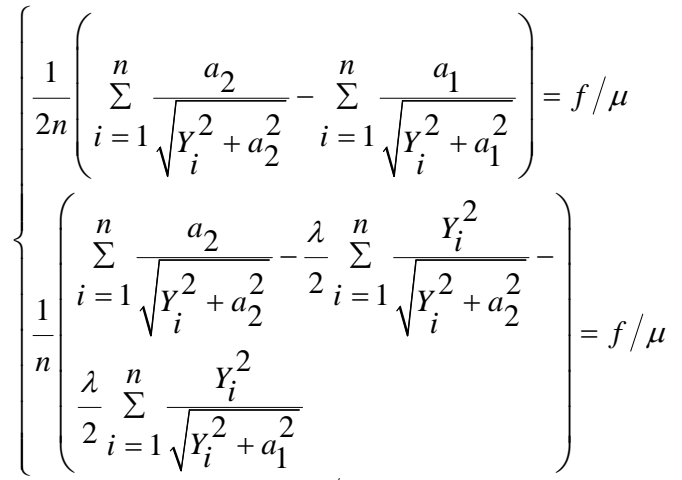

In (13)、 (14), when $\lambda, f / \mu_{\max }$ of two equations have been known, there are two unknowns $\alpha_{1}, \alpha_{2}$ corresponding to a relative steering radius $\rho$, it shows that the equation set can be solved. The transcendental equation can be solved by using the numerical computation to obtain the numerical solution

\section{CALCUlation OF TYPICAL STEERING THE PROCESS}

The parameters of two assumptions are shown in table I.

TABLE I. PARAMETER TABLE

\begin{tabular}{|c|c|c|c|}
\hline Weight (Kg) & 36500 & $\begin{array}{c}\text { number of provisions } \\
\text { steering radius }\end{array}$ & 2 \\
\hline $\begin{array}{c}\text { The length of } \\
\text { track-contact- } \\
\text { ground }\end{array}$ & 3.84 & Work radius of driver wheel & 0.2835 \\
\hline $\begin{array}{c}\text { Center-to-center } \\
\text { distance of } \\
\text { track(m) }\end{array}$ & 2.64 & $\begin{array}{c}\text { resistance coefficient of } \\
\text { ground }\end{array}$ & 0.0382 \\
\hline $\begin{array}{c}\text { The number of } \\
\text { roadwheel }\end{array}$ & 5 & $\begin{array}{c}\text { maximum steering resistance } \\
\text { coefficient }\end{array}$ & 0.49 \\
\hline $\begin{array}{c}\text { Note: from car to tailstock, the relative positions of roadwheel along the } \\
\text { track-contact-ground is } \mathrm{y}_{1}=\mathrm{y}_{5}=1, \mathrm{y}_{2}=\mathrm{y}_{4}=1 / 2, \mathrm{y}_{3}=0 \text { 。 }\end{array}$ \\
\hline
\end{tabular}

A. Relative lateral offset of the steering pole relationship relative steering radius

By the balance of force and torque, we can establish a steering equation, and use iterative methods to get the relationship between relative lateral offset of the steering pole and relative turning radius for figure 2

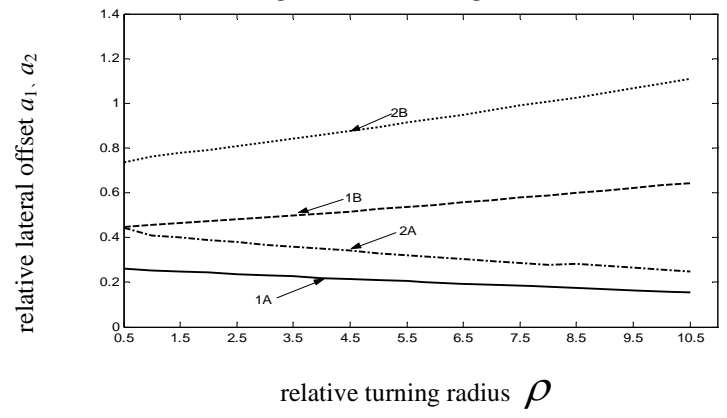

Figure.2steering-center relative deviations vary with relative steering radius with uniform pressure and concentrated load respectively

In figure 2, 1A,1B correspond to the relationship of relative lateral offset of the steering pole $\alpha_{1}, a_{2}$ and relative steering radius with uniform pressure respectively; 2A,2B correspond to the relationship of concentrated load respectively.

Figure 2 shows that in the same hard ground, compared to the distribution of concentrated load and uniform load distribution, the former has bigger lateral offset of the steering.

B. The relationship of traction force, brake force with relative turning radius

Calculation results show that traction force and brake force under concentrated load distribution is bigger than that under uniform pressure distribution by figure 3 .

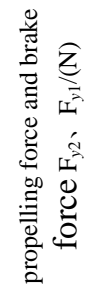

Figure.3 propelling force and brake force vary with relative radius with uniform pressure and concentrated load

C. The relationship of steering resistance moment and relative turning radius

Calculate the relationship of steering resistance moment and relative turning radius by above formulas

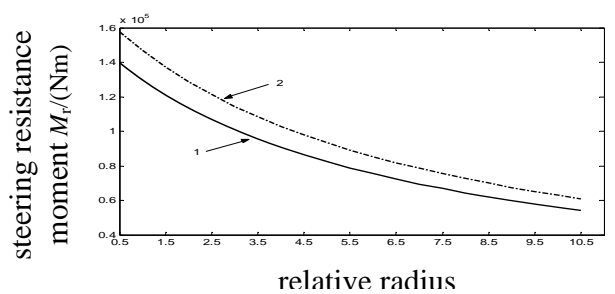

Figure.4 steering resistance moment vary with relative radius in the state of uniform pressure and concentrated load

In figure 4 , curve 1 corresponds to the relationship of steering resistance moment and relative turning radius under uniform pressure distribution; Curve 2 corresponds to the relationship of concentrated load distribution.

The resistance moment under concentrated load distribution is bigger than that under uniform pressure distribution, and it reduces along with the relative radial turning increases..

\section{Turning radius and steering angular speed}

Tracked vehicle steers stably on the given horizontal hard ground by 2 grades, The engine speed fixes in $n=1800 \mathrm{r} / \mathrm{min}$, the steering speed ratio is $\mathrm{Kv}=1 / 1.42$, so the winding speed 
of outside track is $\mathrm{v}_{2}=14 \mathrm{~km} / \mathrm{h}$. the calculation results are shown in table 2

TABLE II. RELATIVE TURN RADIUS AND STEERING ANGULAR SPEED

\begin{tabular}{ccc}
\hline & $\begin{array}{c}\text { Uniform } \\
\text { distribution }\end{array}$ & $\begin{array}{c}\text { Concentrated } \\
\text { pressure }\end{array}$ \\
\hline$\rho$ & 4.302 & 4.4 \\
$\dot{\theta} / \mathrm{rad} \cdot \mathrm{s}^{-1}$ & 0.295 & 0.24 \\
\hline
\end{tabular}

From the results, compared to uniform pressure distribution, turning radius is bigger and steering angular speed is smaller under concentrated load distribution

\section{EXPERIMENTATION AND VERIFICATION OF STEERING MODE}

Conduct a tracked vehicle steering test at the test site for the same tracked vehicle, verify the credibility of the steering kinematics and dynamics model established above.

Glued strain gauge torque transducer on the vehicles side reducer to measure the torque of both sides driving wheel axles, install the photoelectric sensor on driving wheel axles to measure the speed of both sides driving wheel. Test site is the horizontal concrete floor, implement anti-clockwise, the clockwise altogether 2 times steering under 1 grade by $v_{1} / v_{2}=1 / 1.42$.the ground parameter is $f=0.045, \mu_{\max }=0.68$.

Takes the mean values of 2 times steering of outside driving wheel $1.707 \mathrm{~m} / \mathrm{s}$. According to the radius of different position of steering track, carried on 4 measurements, takes its mean value $R=11.62 \mathrm{~m}$.The test system measured the changes of driving wheel on anti-clockwise steering for figure 5. Tracked efficiency $\eta_{t}=0.93$. Transforms the torque into traction force and brake force of inside and outside track, takes its mean value, calculated results can be seen in table III

TABLE III. COMPARISONS BETWEEN CALCULATION AND EXPERIMENTAL RESULTS

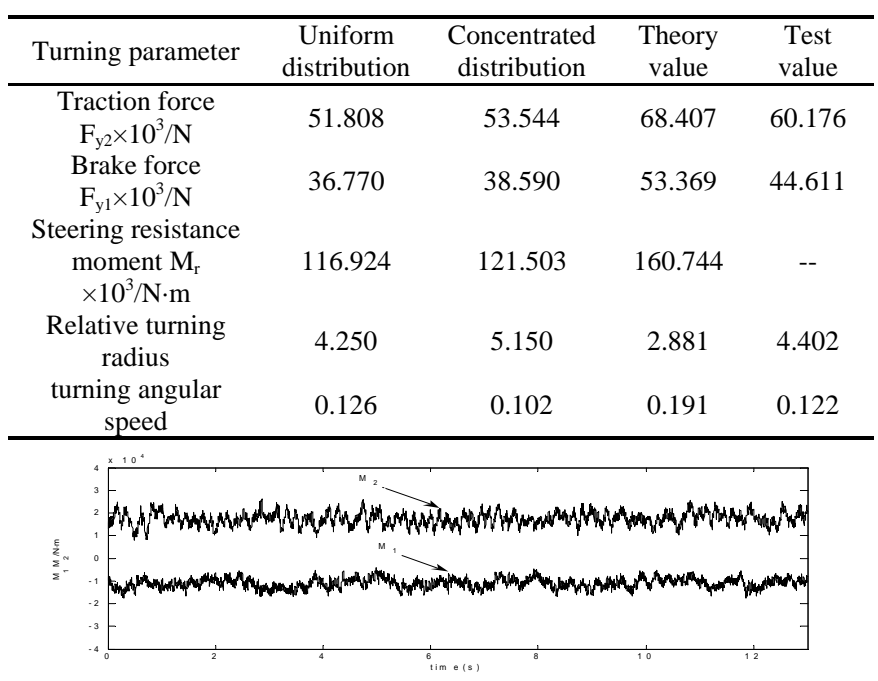

Figure 5 torques of two sides' sprockets vary with time in steering test
In figure $5 \mathrm{M}_{2}$ is the torque of outside driving wheel, $\mathrm{M}_{1}$ is the torque of inside driving wheel,

The conclusion of comparing is showed by table 3

From the data of table 3,we can know that the situation using traditional theory will bring a large calculation error, and it causes difficulties for the evaluation of the vehicle steering performance..This is mainly caused by the increase of actual turning radius. when the slip is considered, turning parameter gets closer to the test value, this shows that the slipping steering model is reasonable.

The calculated value of traction force, brake force under uniform and concentrated load distribution considering the slip of track-contact-ground are smaller than test value, these results are closer to the test value we can summarize that the concentrated distribution suits the actual situation more .

\section{CONCLUSION}

A. The turning parameters considering the slip of trackcontact-ground are close to the test value, thereinto, the error of turning radius under the uniform pressure distribution is $3.45 \%$,the error of turning angular speed is $3.27 \%$,it shows that ,the slipping model established is reasonable

B. The value of turning radius under uniform pressure distribution considering the slip of track-contact-ground is 1.47 times of the traditional theory value ,the value of turning angular speed is $66 \%$ of the traditional theory value, it shows that traditional theory calculation will bring a large error, it causes difficulties for the evaluation of the vehicle steering performance and actual using.

C. The concentrated load distribution compared with the uniform pressure distribution, traction force, brake force, steering resistance moment, relative and turning radius of the former is bigger , and turning angular speed is smaller, namely when the vehicle is steering ,the skid and slip of track-contact-ground is bigger, driving wheel needs more torque, this result shows that concentrated load distribution suits the actual situation more on the hard road steering.

\section{REFERENCES}

[1] WANG Ming-de ZHAO Yu-qin ZHU Jia-guang.Theory of Tank locomotion[M].Beijing:National Defence Industry Press,1983:2935(in Chinese)

[2] W.Merhof E.M.Hackbarth. Mechanics of Tracked Vehicles locomotion[M].HAN Xue-hai LIU Kan ZHOU Yu-long Translation.Beijing:National Defence Industry Press,1989:67-95(in Chinese)

[3] WONG J Y.Theory of ground vehicles[M].Canada:John Wiley \& Sons Inc,2001:390 420

[4] SONG Zhen-jia.Steering Theory of Tracked Vehicle with Uniform Pressure Distribution on Hard Land[J].Aromed Force Technological Institute Education and Scientific Reaserch,1980(3):1-10(in Chinese)

[5] CHENG Jun-wei GAO Lian-hua WANG Hong-yan . Analysis of Tracked Vehicles Steering Considered Tracks` Skid and Slip [J].Journal of Mechanical Engineering,2006: supplement (42),192 195. 
[6] CHENG Jun-wei GAO Lian-hua WANG Liang-xi etc.Analysis of Tracked Vehicles Steering at a High Speed Considered Tracks' Skid and Slip[J].Vehicle and Power Technoligy,2006,1:44 48 